\title{
Negotiating Intimacy, Equality and Sexuality in the Transition to Parenthood
}

\author{
by Charlotte Faircloth
}

\section{University of Roehampton}

Sociological Research Online, 20 (4), 3

$<\mathrm{http}: / /$ www.socresonline.org.uk/20/4/3.html>

DOI: $10.5153 /$ sro.3705

Received: 9 Dec 2014 | Accepted: 12 Jun 2015 | Published: 30 Nov 2015

\begin{abstract}
Whilst both 'parenting' and 'intimacy' have been explored extensively in recent social scientific research (for example, Lee et al 2014,Gabb and Silva 2011), their intersections in the context of family life remain curiously absent. This paper presents findings from on-going longitudinal research with parents in London, which investigates how the care of children, and particularly the feeding of infants, affects the parental couple's 'intimate' relationship. In particular, as part of this special section, it looks at couples' accounts of sex as they make the transition to parenthood, as a lens on the themes of gender, intimacy and equality. Far from being an easy relationship between them, as predicted by some scholars, this research shows that they are in fact, 'uncomfortable bedfellows'.
\end{abstract}

Keywords: Parenting, Gender, Intimacy, Equality, Sex, Couples

\section{Negotiating intimacy, equality and sexuality in the transition to parenthood}

\section{Based on longitudinal work with new parents in London, this paper draws on research which} investigates how the care of children, and particularly the feeding of infants, affects the parental couple's intimate relationship. To that end, it brings together two (traditionally distinct) bodies of literature - one calling attention to a shift in British parenting culture towards a more 'intensive' and 'child-centred' form of care, the other, looking at changes to intimate relationships in an age of 'reflexive modernisation' and greater gender equality. Specifically, this paper focuses in on couples' accounts of sex as they make the transition to parenthood, as a lens on the themes of gender, intimacy and equality. intercourse often serves as a barometer for couples in how they assess the quality of their relationship (Weeks 1995). In line with other papers in this special section, then, the research shows that far from being a straightforward correlation between gender equality and greater intimacy, (as predicted by Giddens et al 1992), the two are, in fact, 'uncomfortable bedfellows', particularly once couples become parents. The article briefly reviews the two bodies of literature, explains the policy context around parental leave and childcare in the UK, discusses the study methodology, and then presents findings, analysis and discussion by way of conclusion.

\section{Theoretical background: Intimacy and parenting}

2.1 As Gabb and Silva (2011) note, the 'conceptual challenge to researchers working in the field of family and relationship studies... is how to carry on building concepts and finding new methods to capture the vitality of personal relationships while keeping sight of the social contexts, patterns and practices of contemporary intimate life' (1.1, 2011). Famously, work by Giddens (1992), Bauman (2005) Beck (1992) Beck and Beck-Gernsheim (1995) and others has explored shifting patterns of intimacy in the contemporary age of 'individualisation'. Broadly speaking, this body of work argued that, in the age of 'reflexive modernisation', there had been a shift away from traditional, patriarchal couple relationships, based on an inherent inequality between men and women, toward a more equitable, mutually fulfilling model, accompanied by the rise of a more 'plastic' sexuality in 
particular (Giddens 1992; this special section). Giddens argued that in the late twentieth century, in the place of traditional patterns of marriage, for example, individuals became more aware of the need for a fulfilling relationship, based on 'confluent love'; one that is active and contingent. The 'pure relationship', which is not bound by traditional notions of duty and obligation, has come to depend, instead, on communication and negotiation. The implication of this work is both that greater equality leads to greater intimacy, and that this is a desirable aspiration for contemporary relationships.

Since this work was published, however, scholars working in the field of family and relationship studies have critiqued the model, arguing for a more nuanced perspective, grounded in the realities of everyday experience. Specifically, Gabb and Silva identify three main strands of thinking which have been particularly influential in shaping and reorienting contemporary UK family and relationship studies over the past 15 years, since the publication of Beck and Giddens' work, including Morgan's notion of 'doing family' as sets of expectations and obligations connected to kin relations (1996); Smart's conception of 'personal life' beyond that of the family (2007); and Jamieson's notion of intimacy defined as 'any form of close association in which people acquire familiarity, that is shared detailed knowledge about each other' (Jamieson 1998: 8).

The last of these is particularly relevant here, specifically as it relates to changes in the division of labour between couples once children arrive. For Jamieson, '[t]he majority of people in Euro-North American societies have lives which are sufficiently privileged to seek 'good relationships' which are not dominated by necessity. However [even then] most personal relationships include a mix of love, care, sharing, understanding and knowing, which involve a degree of relying on, needing or depending on the other, if not desperate necessity' (1998: 174).

2.4 The intention here is to bring this perspective on intimacy to bear on the subject of parenting, my own area of research to date (Faircloth 2013). The underlying argument of that work was that there has been a significant shift in 'parenting culture' in the UK over the last twenty years. The word 'parent', for example, has shifted from a noun denoting a relationship with a child (something you are), to a verb (something youdo). Parenting is now an occupation in which adults (particularly mothers) are expected to be emotionally absorbed and become personally fulfilled; it is also a growing site of interest to policy makers, thought to be both the cause of, and solution to, a whole host of social problems (Lee et al 2014). 'Ideal' parenting is financially, physically and emotionally intensive, and parents are encouraged to spend a large amount of time, energy and money in raising their children, often with the aid of 'experts' (Hays 1996). Whilst this ideology of parenting is not carried out by all parents, or affects all parents in the same way, it nevertheless serves as an ideal standard to which all become accountable (Arendell 2000). This 'intensive parenting' climate, as several scholars have now argued, has changed how parents experience their social role, to the point that one's style of parenting has become more and more central to adult 'identity-work' (for example, whether one is a 'Tiger Mother', an 'Attachment Parent' or a 'Gina Fordist ${ }^{[1]}$ '). Drawing on Goffman (1959) this term is used in place of a more static 'identity' to highlight the active processes by which identity is constructed, and the inherently social nature of this enterprise, as opposed to being simply a means of self-expression (Faircloth 2013).

2.5 Accounts of the development of this 'intensive parenting' culture, including my own, have emphasized how it influences mothers in particular, noting how the demands placed on women in their role as mothers have intensified as women have continued to enter the labour market (rather than decrease, as one might expect). Partly as a means to counter this imbalance, which sees women working the 'double shift' Hochschild (2003), British society has witnessed the construction of the 'involved father' - mirroring, to some extent the more familiar 'intensification' of motherhood (Dermott 2008, Miller 2011). Men are increasingly encouraged to be 'engaged' in childcare, with a particular emphasis on the importance of creating a close emotional connection with children, in place of the more traditional model of the patriarchal breadwinner (Dermott 2008, Lee et. al 2014). Involved fatherhood is also promoted as a means of building stronger communities, with a particular concern about rates of single motherhood in poorer communities (BBC 2007). Not surprisingly, then, accounts from sociologists reveal that fatherhood is becoming more and more central to men's 'identity work' in their accounts of personal life.

2.6 Yet whilst discursively fathers may be encouraged to be 'involved' in parenting and take more of an equal load of childcare, in reality, it is women who continue to shoulder most of the responsibility for this (Dermott 2008, Lee et. al 2014). It is women who typically take extended periods of time away from paid work, and move to part-time hours when they do return to the work place, if they return at all. What is more, despite this emphasis on the importance of splitting responsibilities, optimal infant care as promoted by the state is an inherently gendered, embodied one: women are strongly encouraged to breastfeed their babies by health professionals and 
policy makers, particularly in the early months, a practice which has a cascading impact on many other aspects of infant care (such as soothing and sleeping).

To heed Jamieson's caution again, then, we need to consider how relationships alter when children arrive, and the increased 'necessity' and 'dependence' they create between partners. How, for example, does 'plastic sexuality' work in the context of parenthood, for both men and women? Does the equitable model of the 'new fatherhood' fit into this picture, or does the reality of life as parents inevitably engender a more traditional family set up? And finally, how does the state provision of care affect couples' 'choices' in this matter? The analysis therefore moves to consider the role of the state in creating and sustaining gender roles in parenting culture.

\section{The policy context: Parental leave and childcare provision}

3.1 Since April 2011 (replacing the previous arrangement of twelve months leave for mothers, two weeks for partners) employed mothers who return to work before their child is twelve months old have been able, in effect, to transfer any outstanding leave (of up to six months) to the father or partner. Her leave is calculated at $90 \%$ of her previous earnings for the first six weeks, the middle 33 weeks at a statutory rate of around £130/week, and then unpaid leave for the final 13 weeks (although some women may have this 'topped up' by their employers). Additional paternity leave is calculated as the last six months of a mother's leave - i.e, three months of statutory leave, then three months of unpaid leave. Currently, the couple can only take this sequentially. In the last few months, however, new proposals have been legislated which will alter this provision again, as of April 2015, so that the couple will have more flexibility in how to divide their leave, with the entire year being taken by the partner, after a period of medical leave by the mother, and/or leave taken concurrently (Guardian 2015).

3.2 Critics have some reservations about this new leave structure, because whilst the discourse is there around equality, the financial support (or supportive bosses) may not be. As Asher says 'Parents may worry about fathers taking the earnings hit involved... Fathers may fear alienating bosses by going on extended paternity leave. Families in which mothers can afford not to return to work earlier than twelve months may be minded to stick with the status quo: habits within the household have already been formed at this stage in the leave period; and women may be reluctant to give up what has been established as 'their' leave.' (2011:52-3). Indeed estimates put the percentage of eligible men who actually take up any or all of this leave at only 1.437.[2]

3.3 Furthermore, after the initial 12-month leave period, parents often find themselves in a more financially taxing situation than before. The average cost for a full-time nursery place/after school club for one child in London in 2014 was $£ 189.16 /$ week, or nearly $£ 10,000 /$ annum, with only a limited amount of this paid for out of pre-tax earnings (Daycare Trust 2014). For many couples, childcare becomes an expense narrowly second to a mortgage repayment. In a city like London, which typically requires a considerable commute to work places, many parents also require 'wrap-around care' in the form of a nanny or breakfast club to cover the period before a nursery opens or when it closes and they are able to reach home. At three years old, all children currently qualify for 15 hours of free nursery care per week (and some 2 year olds do in deprived areas), although this frequently has to be taken in regular shifts (for example, five mornings between 9am-12pm), which clearly requires considerable top-up if both parents are working.

3.4 Where childcare is largely seen as the responsibility of the family (as opposed to a state provision, as it might be in other European countries, for example), it will clearly sit uncomfortably with a dual-earner family setup. The cost of care in the UK means that for many couples, what makes 'most sense' is for the lower-earner to be the one who cuts back their hours, or stops work entirely, whilst the other acts as a breadwinner, particularly if they have more than one child. (It is worth reiterating here then that whilst it is more noticeable after the birth of children, a gender pay gap continues to exist before this point too). Indeed, even for those in professional occupations, and earning over the average wage (£476/week or $£ 24,750 /$ annum)[3], the reality is effectively to start living on the equivalent of one salary anyway - either because one person stops work entirely, or because one salary's worth of post-tax pay is spent on childcare.

\section{Methods}

4.1 This paper presents preliminary findings from an on-going study which includes repeat in-depth interviews with 30 participants (15 first-time parent, heterosexual couples), one-off interviews with a further 10 participants ( 5 couples who were lesbian, gay, and/or second time parents), and a survey with a sample of 125 parents (distributed via Qualtrics to a demographically diverse panel of parents in the UK with children under a year old). The intention of the study as a whole was to explore the relationship between gender, equality and 
intimacy as couples make the transition to parenthood.

Where other publications from the project look more specifically at the corrosive effect of this childcentred parenting on the couple relationship, or at the theoretical contradictions of policy measures designed to promote 'equality' in parenting, this paper looks more specifically at sexuality - an emergent theme from the interviews with (some) couples when asked about 'intimacy'. The focus is on the accounts of the dual earner heterosexual professional couples who are first time parents, and on a selection of those couples in particular to explore the issues at hand in depth, and map directions for future research. In addition to being those who spoke most openly about sex, these were couples who most readily seemed to embody the conflicts between intimacy and equality, magnifying many of the tensions common to the sample as a whole, as I explain below. The analysis here therefore focuses on a sub-section of the main sample, in part as a result of this grounded and iterative approach to data collection and analysis.

Drawing on past work, I was particularly interested in finding parents who internalise the injunction to 'do parenting' in line with expert advice, and who consciously reflect on and articulate their decisions as an element of their 'identity work'. Furthermore, I wanted to work with couples who would technically be able to afford an 'equitable' division of parental leave, even if they chose not to. Bringing together these aims, I contacted parents through a range of antenatal education classes and courses in London - such as the National Childbirth Trust, recognised by a number of scholars (for example Kitzinger 1990; Thomson et al 2011) as being primarily made up of this demographic.

4.4 I interviewed these couples in various areas of London[4]. After meeting one or both of them at an antenatal group or similar, and a discussion with the aid of a study information sheet, couples were asked to fill out a brief online survey (designed and administered via Qualtrics) to collect demographic data, using sections from the 2011 census as a template (e.g., age/marital status etc). These couples were then interviewed, usually in their homes, at times convenient to them. The first interview (both together and separate) was before their child was born, and then jointly when their child was 1-2 months old, at 6 months old, and then finally at 11-12 months old, when we also repeated the individual interviews. Recordings were transcribed and coded, with the aid of relevant software. More recently, I have contacted the couples again to ask for their experiences of childcare, now that their children are 2-and-a-half years old, and on the cusp of the 15 hours free provision, to ask whether this would make any difference to their current domestic/working arrangements. Around a third of these couples are now expecting their second child, which will feed in to the results of the study moving forward.

4.5 I also refer to the interview material from the heterosexual dual-earner professional couple expecting their second baby. Much research with second-time parents has noted that that the 'ideal' picture of parenting and gender norms, so strong for first time parents, tends to be a more pragmatic one for these more experienced couples. Seeing how parents have negotiated parental leave and childcare arrangements over the course of several years also gives an interesting contextualisation on the parental leave measures available to new parents.

4.6 Of course, one of the key problems with writing about parenting, intimacy, or indeed any aspect of family life, is how to go about accessing it at all. Analytically and methodologically, I drew on inspiration from Gabb's discussion of 'interactive' interviews (2010) and have taken a largely narrative approach to research here. Many scholars have emphasized the role of language in the constitution of personhood, and have argued 'that human beings actually live out their lives as 'narratives', [and] that we make use of the stories of the self that our culture makes available to us to plan out our lives... to account for events and give them significance, to accord ourselves an identity' (Rose 1999: xviii). Looking at how couples 'accounted' for the division of labour within their respective partnerships was the intention of the study, analysing both anticipation and outcomes before and after children were born.

4.7 Nevertheless, there are clearly limitations to the interview method, particularly when talking about sensitive issues. The intention was to study intimate practices generally but not necessarily sexual practices. As a rule, I did not ask couples directly about their sex lives, but rather, would open the space for them to address it, either together or separately (on the whole, this topic was easier to broach with mothers in one-on-one interviews, rather than with couples or with fathers). Typically, this would involve asking a question such as 'Given this study is titled 'Gender, intimacy and equality' could you tell me what those terms mean to you?' It was interesting, however, that for most couples that the word 'intimacy' was taken as an invitation to discuss sex, even though this was not directly intended. Indeed, the assumption that intimacy meant sexual intercourse gave rise to this paper, with the couples featured here being most open about their expectations and experiences of 
this topic. Again, this points to some interesting assumptions around what sex is taken to stand for in relationships, as is discussed further below.

\title{
Demographic profile
}

The majority of the couples interviewed - and on whom the analysis here is based - were largely middle class (in that they overwhelmingly had higher educational qualifications and professions) middle aged (between 45 and 29 though typically 34 or 35), white, heterosexual and married (all were living in long-term relationships, though if they were not married 'partner' was used, rather than 'husband' or 'wife'). The average household income for the group ranged between $£ 30,000$ (in the case of a couple where the wife was undertaking a PhD) and over $£ 200,000$, with the majority between $£ 50,000$ and $£ 150,000$. All interviews were conducted in English, though some participants were born outside the United Kingdom.

4.9 As might be imagined, these couples demonstrated the sort of attitudes that the current policy around parenting tries to foster: that it is an intensive, fulfilling and rewarding activity that both parents (notably fathers) should want to be 'involved' in (a word that cropped up a lot). That said, however, these 'attitudes' around equality appeared to be aspirational, rather than enacted in a practical sense (clearly chiming with the kind of 'identity-work' fostered in the more reflexive age, mentioned above). The majority of couples stuck to the traditional division of parental leave - with mothers taking longer periods than fathers in all cases, and only one couple seeming to know about the possibility of splitting leave more equitably. This is discussed further elsewhere, but clearly this raises some interesting questions around choice, accountability and preference (that is, how far these decisions are pragmatic, and how far they are what each partner 'wants').

\section{Accounts: Intimacy and sex}

5.1 In reading literature from the area of sexuality studies in preparation for writing about this aspect of the study, it quickly became apparent that much of this concerns desire or sexual identity. There was less on changing patterns of sexual activity over the lifecourse. To this extent, this paper - like Van Hoof's in this special section - contributes to what Jackson calls the 'everyday' aspect of studying sex and relationships 2008). In particular, these findings reveal the importance of sexual intercourse for couples as a means of assessing the strength of their relationships (Weeks 1995). It therefore maps the ways anticipations around sexual intercourse matched up (or not) with realities once children were born, as a lens on changing understandings of intimacy and equality. These accounts are foregrounded as evidence of a cultural contradiction between the competing ideologies of intensive parenting, gender equality and fulfilling intimate relationships.

5.2 Providing a useful introduction to this subject is Clare, the only mother cited in this paper to have had a child already. She works full-time as a secondary school teacher, having taken 6-9 months of leave with each child, and talks about how important sex is for her and her husband - not only in the sense of being a physically pleasurable sensation, but more for what it represents for them:

\begin{abstract}
Clare: No, but do you know what? It's so important to have sex in a relationship. You just always come back to it because if you don't you are very, very good friends and there's that intimacy lacking. [My husband] and I get scratchy with each other and we lose our connection when we don't have sex frequently and regularly for me. If we manage once a week I'm really proud of that and that's pretty good, that's what we do. I'm really quite...I feel quite proud of that. Sometimes it goes down to every couple of weeks but if it's not every couple of weeks then we both get really sad.
\end{abstract}

5.3 In what might be referred to as a hierarchy of intimacy, (penetrative) sex with a partner has come to symbolise the pinnacle of intimate relations (as opposed to, say, cooking for each other, sleeping in the same bed or massage, which might be others sorts of 'intimate' behaviours) (Weeks 1995). She continues - with the benefit of hindsight as a second time mother - to talk about how this changes over a couple's relationship, in terms of what it symbolises:

\footnotetext{
Clare: It comes to symbolise such different things, like when you first meet somebody you're at it all the time and it's a kind of bonding, it's a really fun thing as well. Then when you move in together you're very cosy and settled. Then maybe when you get married it will happen more. Then when you want to have a baby you will have sex all the time and it will become a military procedure but [then] you will probably start enjoying it again.
}

\section{Anticipation and reality: Accounting for dissonance}

5.4 Like the other stages Clare mentions, it was certainly true that having children meant a major shift in sexual practices for most couples. This was something that was anticipated (albeit without much clarity as to 
what these changes would actually be) during pregnancy by many first-time parents. Interestingly, many couples were confused as to how to negotiate actually having sex with the physical presence of a new baby in their bedroom (the ideal sleeping arrangement parents are advised to adopt for the first six months). Like Lucy, below, couples often spoke about the importance of maintaining their regular patterns of sex, which they hoped would get back to normal after the disruption of pregnancy, birth and/or breastfeeding. Already on her anticipated yearlong maternity leave from work at one of the large trade unions, she is speaking a few days before she gave birth to her first baby here:

\begin{abstract}
Lucy: ...you were asking about how you think it's going to affect your relationship, one of the reasons I was saying about the bed and sharing thing is the sexual aspect of it and I don't want that to get lost although it has recently, he's been really worried about hurting me or the bump, he's been a bit put off things, and I guess that's one of the things that worries me most about breastfeeding is your breasts going from being this sexual thing to a feeding practical thing for the baby, so I think that's one of my worries about our relationship and about breastfeeding...So we want to try and make an effort ... That's the other thing ... you shouldn't even like leave the baby on its own in the room, not even to have a shower, I mean I don't know what you're supposed to do, but if you want to have sex or whatever, are you supposed to have the baby in the room? I haven't thought very hard about it but ... I'm sure you can leave the baby to have a shower for 10 minutes.
\end{abstract}

Despite some awareness about embodied changes, unfortunately the experiences of post-baby sex were worse than expected in some cases, and many women I spoke with were totally shocked by how their bodies had undergone what one mother described as a 'total physical onslaught', which they felt totally unprepared for. Speaking when their baby was around 6 weeks old, this couple, who work in HR and fashion design respectively, point out not only the physical barrier to having sex, but emotional and practical ones too:

Katie: Ah yeah. I feel I'm neglecting [him].

Paddy: No you're not.

Katie: And because of that I have the episiotomy, I'm really scared about having sex...So that's really sort of...But I mean it hasn't even been for six weeks yet...I am scared. It feels like it's going to be months, if not years. So, ...so yeah. But even the thought of having sex because she's in the bedroom, I don't even know how it would work really. Seems a bit weird. So, yeah that's a bit strange. And yeah it does just feel like you don't get any time together. You're just talking about what you going to have to do now. 'Do you want to cook dinner?' 'I'll wash up'. That's it really. 'Do you want to change the baby's nappy?' 'Do you want to hold the baby?'

The same mother said at 6 months (as the main earner, she returned to work full-time when her baby was around 10 months, whilst her partner worked part-time, and their daughter attended a nursery part-time):

\footnotetext{
Katie: We've only had sex three or four times since she's been born and I didn't think that would fall apart the way it has. But it is just timing and opportunity and not feeling tired and being in the same room. If we had our own room, it might be different...And the episiotomy is quite painful.

Author: Is it still quite sore?

Katie: Well, it was last time! I think all those things have contributed to ... and that really worries me because you need that for a healthy relationship...I think I knew that it would put a strain on the relationship but you can't really imagine it happening until it has happened. And my sister just kept saying everything that's wrong with the relationship is magnified when you have children and she's going through a really bad patch with her husband. So I did know to expect it and I don't know, it is good and it isn't good. But I think it's not helped by [his] working pattern and that situation, by him being around but not really being there to help, it's made me a bit resentful.
}

\title{
Intimacy and inequality: Embodying difference
}

Like Clare, we can see here that Katie uses how often she has sex with her partner as a barometer for the relationship as a whole. This points to the way in which a 'good sex life' is linked to notions of a 'healthy relationship' - and something to be 'performed' (in the sociological sense) both to each other as partners, and to friends, family (and researchers) as peers. Like Woodiwiss's research, then (also in this special issue), we see how powerful the discourse of 'compulsory sexuality' can be for individuals, at all stages of the life course. This comes from Cathy, a 32-year-old academic at a London university, who planned to take 6 months off work, and then return 4 days a week. Her husband, a 31 year old IT manager in a bank, was planning on taking 2 weeks of statutory leave, and then also moving to a 4 day week when their baby was 6 months, so that they each do a day of childcare, with a nanny or relatives covering the other three days. At this point she earned around $£ 45,000$ he earned around $£ 95,000$. 
happens to your body. Whereas other people, like Libby, had a reasonably quick and easy birth. Was back having sex all the time within about a week or something. And they were just like, back on the....and their...they put Alice out in the other room, after five weeks or something, because it was ruining their sex life. I was just like, I'm not...but she was sleeping through the night from, like, three weeks old. They just had a whole completely different experience. So I know that it can be the ideal thing. That does happen. [...]

Colin: It could be that she's lying to you.

Cathy: No. She told [Emma].

Cathy also talked about the physicality of motherhood (and breastfeeding, in particular) coming as a shock, and a limit on her 'intimacy time' with her husband, which made her feel less desirable, something many women reported as a problem of the 'mother/lover' division. She describes the shift from bodies being conduits of pleasure to being sources of nutrition particularly graphically here:

Cathy: Yeah. My body was alien to me for a period of time. I embraced it more when I was pregnant, I was annoyed by it but after, particularly with the breastfeeding, you can't take your bra off ever. With mine, because I had such a milk supply and I'd have to wear those breast pads all the time and how many would I get through in a day, six or seven?... So we were buying stacks and stacks of them and as soon as I'd take my bra off, I'd go into the shower, I'd just be squirting everywhere so it makes physical intimacy very difficult.

Whilst I do not expand on it here this couple had quite an interesting experience of the division of childcare. They trialled their '4-day week each' arrangement by using some of their holiday allowances, though sadly - and perhaps tellingly - when her husband requested the arrangement on a more permanent basis, he was made redundant. This meant that he had a period of several months at home, without work (but with a generous payment package; and interestingly, rather than a period of full-time childcare; a nanny 3 days a week). He subsequently found another job, working 5 days a week.

5.10 Given that they were so busy, they talked at length about how important it was for them to schedule other sorts of 'intimacy time', including, but not limited to sex, particularly because they could no longer be spontaneous in spending time with each other, and that their son would 'take all of their attention' otherwise:

Cathy: [Speaking to her husband] But even with [our son], if you were with him, I could quite easily come into the room at the end of the day and just give [our son] all of my attention and not even kiss you hello. And it would happen the other way round too. He takes all of our attention, you have to remind yourself that the other person is right there and needs to be greeted and made into a person by actually being recognised!

\section{Negotiating cultural contradiction}

5.11 It is also interesting to note here the inherent contradiction between government advice to mothers around breastfeeding and the ideological commitment to 'shared' parental leave. (Exclusive breastfeeding for six months and anything up to two years or beyond clearly not being the easiest of activities to split according to a $50 / 50$ model or similar). As we can see from these accounts, new parents often find themselves at the juncture of several competing cultural discourses: one around the importance of intensive, embodied care carried out by biological mothers, particularly as it relates to feeding; another about the importance of gender equality at home and work, particularly as it relates to providing 'child-centred' care; and another around the importance of maintaining a healthy couple relationship, particularly as it relates to having regular sex. No wonder many of them reported feeling tired and 'torn'.

5.12 If there was a 'typical response' amongst this group of new parents, then, this couple probably best capture it. Reflecting on working full-time in the charity sector and taking on full-time childcare (whilst training to be a certified child minder in place of returning to administrative work) respectively, Mark writes:

Mark: Well, we don't have as much sex as we would like. [My wife] in particular is always tired, and I am pretty tired too so am often easy to put off! However we try to schedule sexytime so that it doesn't fall off the radar, as it easily could. We both realize the importance of this, as when we didn't have sex for some time after the birth of [our daughter], we felt that our relationship changed. I wouldn't call it deteriorating, but we just didn't feel as close to each other in a way, which we missed. Maybe we felt too much like a 'team' and a little less like lovers! So we are less impulsive, but if it was left to chance it wouldn't happen! We are getting more time on our own recently, due to family members taking her away for weekends and longer, so that too is changing.

\section{Discussion}

6.1 In her study, When Couples Become Parentsbased on interviews with couples in Canada, Bonnie Fox 
also observed that there was a 'dramatic change in sexuality' during the first year of parenthood for most of her participants (2009:249), a loss that was more keenly felt by men. Women's need to recuperate, their tiredness, and the fact that they were breastfeeding reduced their desire for sex. And even when they did have sex, it was different to before, clearly chiming with the set of accounts here around expectation not matching up to reality.

Developing a useful typology, Fox notes that these changes in sexual activity were indicative of other kinds of changes that occurred in couples' relationships as they negotiated the first year of parenthood. In the first pattern (around 30 percent of couples) the relationships deteriorated, and were 'riddled with tension and worn down by the upset and anger of one or both partners' (2009:252) In these cases, she describes relationships on the brink of divorce, or 'nonexistent'.

6.3 In the second pattern, made up of around 25 percent of couples, the relationship was marked by tension between the partners, but 'there was no noticeable weakening of the relationship over the year. Often the anger was about the men's avoidance of the newly expanded housework, for example, and it created tensions that were new to these relationships. Nevertheless, these couples' happiness about being parents sometimes meant that they - especially the men- felt closer to their partners' (2009:252).

6.4 In the third pattern, which comprised another 25 percent, the relationships neither seemed to weaken or strengthen, but 'clearly suffered from the absence of time for intimacy' (2009:252). 'In these relationships, there was only minimal tension between partners - usually blamed on tiredness - but both people found the year to be difficult emotionally, given how little time they spent together.'

6.5 Lastly, in the final 20 percent were couples whose relationships were improved by parenthood. These were couples who experienced parenthood 'largely as an addition to their relationship' (2009:252)

6.6 What Fox notices is that in those couples that displayed the first pattern, there was a lot of anger and resentment. This was 'fostered by the gender-based divisions organising their daily lives and sometimes enhanced by the insularity of their families... men's detachment from the care of their babies and the dramatic differences in the men's and women's daily experiences - especially when the women were home full-time were usually what undermined mutual understanding and often support. When both parties were stressed by the high demands of their daily work, that stress could further erode empathy, negate any hope of mutual gratitude, and produce considerable anger' (2009:265).

\section{Less equality, less intimacy? Accounting for cultural contradiction}

6.7 Fox's typology is useful in understanding the accounts presented here. The issue of 'resentment' and feelings of inequality and unfairness were demonstrated by participants such as Katie, above. Writing about the emergence of the 'companionate marriage' (as opposed to the more traditional patriarchal one), Collins (2003) notes that 'The keywords of companionship were intimacy and equality. Intimacy was at once achieved and expressed through privacy, closeness, communication, sharing, understanding and friendship' (Collins 2003:24). However, he identifies a problem with this once children come along: parenthood accentuated the sexual division of labour and had the potential to divide companionate couples every bit as profoundly as their patriarchal counterparts. Whereas spouses were able to live 'almost identical lives' before they had children, any resulting intimacy came under pressure from the inescapable differentiation between the two sexes once there is a child.

6.8 Particularly if women were earning less than their partners before (which in all but one case they were) what usually emerged from the interviews is that it made 'most sense' that they were the ones to take time off work, or stop work entirely. Many women 'accounted' for this in an understandably contradictory way as they went about trying to narrativise it; it was both what they 'wanted' to do, and what they 'had' to do: They had an ideological commitment to equality in career opportunities, yet a gendered 'pull' towards a model of intensive parenting (or, motherhood).

6.9 It is important to contextualize these accounts in our particular historical moment, then. In line with much sociological and popular literature, the accounts here show that the transition to motherhood is felt particularly acutely by many women today (for example, Cusk 2001, Miller 2005). This is, no doubt, in part as a reflection of the shift Giddens et al identify - the period before children is (discursively at least) one of equality for contemporary men and women, particularly in the middle classes: women match their male counterparts through the education system and (largely) have professional opportunities unfettered by gender, being able to gain financial independence. Furthermore, they have freedom in romantic and sexual unions and are able to express 
6.10 As the narratives point to, however, something happens around the time of motherhood that means that many women suddenly 'get' feminism, and indeed their biological difference to men in a more explicit way than in the past (Bristow 2008). Bodies, which had so far been a marker of the self (and self-control) started to 'betray' them, as Cathy puts it. This realisation of biological difference - that Cathy points to in her account - is often accompanied by a shift from being financially independent towards dependence whilst on maternity leave. Similarly, when she does go back to work, like many other women in the sample, Cathy sees her career fall more readily into the 'mummy track' of a 4-day week, where her husband continues with the same 5-day pattern, despite an ideological commitment (and practical agreement) around the importance of career parity for both parents.

6.11 Furthermore, housework is no longer a case of taking 'turns' to carry out chores, but a hugely expanded task which has to be carefully orchestrated to keep all household members fed and clean. The invisibility - and cultural de-valuation of - this labour after motherhood is something many other women in the sample also expressed resentment about, feeling that their partners simply 'didn't see' the extra work they were doing, often by virtue of being the ones at home more often. These material and practical changes to women's financial situation (despite being coupled with a policy emphasis on 'equal parenting') often serve to magnify this sense of injustice. And clearly, for many women, losing their previous identities as workers could create its own kind of challenges here.

6.12 This has an impact on intimacy, as expressed through sex. So, where before, sex is something that is 'kind of fun' and 'bonding' for couples, as Clare puts it, afterwards, Katie talks about it like more of a gendered currency, or something she feels she 'owes' her partner, despite feeling physically uncomfortable. (It is notable too that at the point she makes that remark, she is being supported by him financially; in this instance, policy has clearly entered the bedroom). Furthermore, many couples are simply too tired, or physically uncomfortable to resume a 'normal' pattern of intercourse.

6.13 In terms of the theoretical contribution of this paper, in part, then, these observations back up the shift Giddens et al describe - clearly, any cultural focus on female sexual pleasure and the fact that many women were able to talk about their sexual needs and desires so openly is proof of a move towards a more equitable focus on mutual pleasure in relationships today than in the past (1992). However, rather than moving in a progressive fashion from patriarchal to companionate to more 'plastic' intimacies, for example, there appears to be some movement back and forwards between these various arrangements, with parenthood often pushing couples back into an unfamiliar patriarchal set up (at least financially, if not ideologically). Clearly, this shift back into a more traditional pattern is exacerbated by a lack of resources - for many couples, there is no choice but to opt for more gender segregated roles. As this paper has shown, however, even in the case where a couple has a joint income of nearly $£ 150,000$ (such as Cathy and Colin) there still seems to be a 'pull' towards these more traditional patterns. It is worth reiterating the impressive power of the intensive mothering ideology in shaping women's perceptions of themselves as good mothers, and working out how they 'want' to arrange their working and home lives. Yet again we see how an equal parenting ideology meshes uncomfortably with a culturally elaborated intensive, embodied commitment to motherhood.

6.14 Similarly, there is clearly a tension between a more 'plastic sexuality' and the transition to parenthood. Whilst Giddens' theory of a more 'pure' relationship might have some purchase on how sex is at least imagined prior to the arrival of children, the idea that the couples here are only in relationships for as long as they are individually satisfying is not substantiated by the account here: clearly parenthood creates demands and necessities that they view as valuable, beyond their own individual sexual pleasure. Most couples acknowledged that the first year of parenthood was a particularly tough time for their relationship, but it was, essentially, a temporary state of affairs that would eventually pass. (Although it is true that if they did not take steps to reintroduce 'sexytime', as Mark puts it, they recognised their relationship would deteriorate). Yet again, we see how policy frameworks, and material resources, therefore shape even the most intimate of our interactions as we go about negotiating these competing ideologies.

\section{Conclusions and future directions}

7.1 These accounts show how couples' experience of changing sexual practices can offer us a lens on the relationship between gender equality and intimacy. Far from being a straightforward correlation between them, they are, in fact 'uncomfortable bedfellows', fraught with frustrations from all sides. In contributing both to the literature around changes to intimate relations and parenting culture, this paper provides evidence that whilst our 
gender roles are less and less scripted before children arrive, they are very often thrown back into traditional models once they do.

7.2 Whilst efforts to make parenting more equitable are clearly laudable, the evidence here seems to imply that current policy is missing the point: even for couples who are ideologically committed to, and can afford, a more equal split there seems not to be an practical commitment to sharing care. This certainly suggests that for those social groups who cannot afford this division that such policy drives will be even more irrelevant (Gillies 2009). What is more, there is a danger that though these moves would be beneficial in giving parents more freedom in how to divide up their time, many of the efforts to involve fathers in childcare appear only to extend a cultural logic around parenting to men - an intensive one, which puts children at the centre of all considerations. This has the potential to leave two parents feeling 'torn', rather than, for example, challenging our view of children as requiring one-on one care by a biological relative, or alleviating a cultural guilt around the place of childcare. This has its own knock-on effect on couple intimacy. Mark and his wife talk about feeling more like a 'team' of partners, rather than 'lovers', as they have little space to think about themselves as a couple beyond being parents to their daughter (although this raises its own interesting considerations around how sexual desire intersects with 'gender equality').

7.3 How 'equality' and 'intimacy' work themselves out in a couple's practices is demonstrably deeply uncomfortable for their 'identity work' as gendered beings, in negotiating dissonance between expectation and outcome. For many parents in this study, struggles around how to negotiate competing cultural discourses about good parenting, about good relationships and about gender equality - are indicative of an interesting historical moment in social life. Rather than showing a straightforward correlation between (or continual progression towards) greater intimacy and equality, these accounts show the two are in a state of flux. As this, and other papers in this section demonstrate, then, attention to these 'everyday' experiences, provide interesting intellectual reflections, far beyond the bedroom.

\section{Notes}

Gina Ford is one of the best selling parenting experts in the UK, advocating a structured approach to infant care, with practices such as scheduled feeding and sleeping routines.

http://www.publications.parliament.uk/pa/cm201314/cmhansrd/cm140403/text/140403w0001.htm Accessed 25.11.2014

http://www.ons.gov.uk/ons/rel//ms/labour-market-statistics/may-2014/info-awe-may-2014.html Accessed 25.11.2014

Ethical approval for the study was granted by the University of Kent's Review Board, in accordance with BSA guidance http://www.britsoc.co.uk/media/27107/StatementofEthicalPractice.pdf

\section{References}

ARENDELL, T. (2000) 'Conceiving and Investigating Motherhood: The Decade's Scholarship', Journal of Marriage and the Family 62(November): p. 1192-1207. [doi:10.1111/j.1741-3737.2000.01192.x]

ASHER, R. (2011) Shattered. Modern Motherhood and the Illusion of Equality. London, Harvill Secker

BAUMAN, Z (2005) Liquid Life Cambridge: Polity Press.

BBC NEWS. (2007) 'Gang Crime 'Due To Absent Dads',' Retrieved 1 April 2011 from http://news.bbc.co.uk/1/hi/uk_politics/6956303.stm

BECK, U. (1992) Risk Society: Towards a new modernity London: Sage.

BECK, Ulrich and Beck-Gernsheim, Elisabeth. (1995) The Normal Chaos of Love. Cambridge: Polity Press. 
BRISTOW, J. (2008) 'Why we need a parents' liberation movement'. Spiked Review of Books. http://www.spikedonline.com/review_of_books/article/5386.

COLLINS, M. (2003) Modern Love: An Intimate History of Men and Women in Twentieth-Century BritainLondon: Atlantic Books

CUSK, Rachel. (2001) A Life's Work: On Becoming a Mother. London: Fourth Estate.

DAYCARE TRUST. (2014) 'Childcare Costs Survey 2014'. London: Daycare Trust http://www.familyandchildcaretrust.org/childcare-costs-surveys.

DERMOTT, E. (2008) Intimate Fatherhood: A Sociological Analysis London: Routledge.

FAIRCLOTH, C. (2013) Militant Lactivism? Attachment Parenting and Intensive Motherhood in the UK and France Oxford and New York: Berghahn Books.

FOX, B. (2009) When couples become parent:s The creation of gender in the transition to parenthoodToronto: University of Toronto Press.

GABB, J. (2010) Researching Intimacy in Families. London, Palgrave Macmillan.

GABB, J. and Silva. E. (2011) Introduction to Critical Concepts: Families, Intimacies and Personal Relationships. Special Issue, Sociological Research Online http://www.socresonline.org.uk/16/4/23.html.

GILLIES, V. (2009) 'Understandings and experiences of involved fathering in the United Kingdom: exploring classed dimensions', The Annals of the American Academy of Political and Social Science, 624, p. 4960. [doi:10.1177/0002716209334295]

GOFFMAN, E. (1959) The Presentation of Self in Everyday LifeLondon: Penguin.

GUARDIAN. (2015) 'Shared parental leave: 'nightmare' new rules, or the first baby steps to equality?' http://www.theguardian.com/money/2015/apr/11/shared-parental-leave-rules-equality Accessed 20 April 2015.

GIDDENS, A. (1992) Transformation of Intimacy: Sexuality, love and eroticism in modern societiesCambridge: Polity.

HAYS, S. (1996) The Cultural Contradictions of Motherhood. New Haven and London: Yale University Press.

HOCHSCHILD, A. (2003) The Second Shift (London and New York: Penguin Books).

JACKSON, S. 2008. Ordinary Sex. Sexualities, 11(1/2), 33-37. [doi:10.1177/13634607080110010204]

KITZINGER, J. (1990) 'Strategies of the Early Childbirth Movement: A Case-Study of the National Childbirth Trust', in Garcia, J., Kilpatrick, R. and Richards, M. (eds), The Politics of Maternity Care: Services for Childbearing Women in Twentieth-Century Britain. Oxford: Clarendon Press, p. 92-115.

LEE, E. Bristow, J. Faircloth, C. and Macvarish, J. (2014)Parenting Culture Studies Basingstoke and New York: Palgrave Macmillan.

JAMIESON, L. (1998) Intimacy: Personal relationships in modern societiesCambridge: Polity Press.

MILLER, T. (2011a) Making Sense of Fatherhood Cambridge: Cambridge University Press.

MILLER, T. (2005) Making Sense of Motherhood: A Narrative Approach. Cambridge: Cambridge University Press. [doi:10.1017/CBO9780511489501]

SMART, C. (2007) Personal Life: New Directions in Sociological Thinking Cambridge, Polity.

ROSE, N. (1999 [1989]). Governing the Soul: The Shaping of the Private Self London: Routledge.

THOMSON, R, Kehily, M.J, Hadfield, L and Sharpe, S. (2011) Making Modern Mothers Bristol: Policy Press.

WEEKS, J. (1995) Invented Moralities, Sexual Values in an Age of Uncertainty. Cambridge: Polity Press. 
